\title{
Evaluate the effect of Implementing Suggested Nursing Teaching Guidelines for Patients Undergoing Liver Biopsy on their outcome
}

\author{
Zienab S. Ibrahim, Madeha A. Mahmmoud \& Ehab F. Abdou. \\ Nursing Supervisor on Ear, Nose and Throat Unit Assiut University Hospital Egypt . \\ Lecturer of medical-surgical Nursing, Adult Nursing Department, Faculty of Nursing,Assiut University Egypt . \\ Professor of Tropical Medicine and Gastroenterology Department, Faculty of Medicine, Assiut University Egypt.
}

\begin{abstract}
Liver biopsy has been an integral part of the management of patients with chronic viral hepatitis. Aims of this study; to assess patient's knowledge about liver biopsy, the effect of implementing suggested nursing teaching guidelines for patients undergoing liver biopsy on their outcome and to evaluate the effect of implementing suggested nursing teaching guidelines for patients undergoing liver biopsy on their outcome. Subjects and Methods:The study was conducted in the Tropical Medicine and Gastroenterology Department and outpatient hepatitis viruses clinic at AssiuUniversity Hospital. Study design:Quasi experimental research design was utilized in this study. The subjects of this study consisted of 200 male and female adult patients. Tool:Structured Interview questionnaire sheet.Nursing guidelines for Patients undergoing liver biopsy. Results:The majority of studied patients were male(85.5\%), ( $72 \%$ ) were married, ( $45 \%$ ) illiterate. The results also revealed that majority of the studied patients had poor level guidelines about liver biopsy with percentage (93.5\%). Conclusion:All studied patients weren't properly prepared prior before taking liver biopsy.Recommendation, further research studies are needed to focus on more nursing guidelines was developed according to the patients' needs that can help patients in provision of a safe and effective care for liver biopsy and improvement patient outcome.
\end{abstract}

\section{Key word: Liver Biopsy, Guidelines \& Nursing.}

\section{Introduction}

Incidence and Prevalence of hepatitis $\mathrm{C}$ is the most common cause of chronic liver disease in Egypt. The nationwide carriage rate in 1997 was estimated at 6 to 8 million, or $18.1 \%$ of the population - the highest rate in the world A study published in 2010 estimated the yearly rate at 500,000 new cases $(0.7 \%$ of the population); while a study published in 2013 estimated the yearly rate at fewer than 150,000 cases. An analysis published in 2009 predicted that 127,821 deaths from chronic liver disease and 117,556 deaths from hepatocellular carcinoma would occur in Egypt over the next 20 years The high rate of Hepatitis C infection in Egypt is largely attributed to previous mass-injection (antimony tartrate) treatment campaigns for schistosomiasis, which involved repeated use non-sterilized needles. $84 \%$ of patients who had received intravenous schistosomiasis therapy during the 1980's were found to be HCVpositive; and anti-Schistosoma antibodies were found in $29 \%$ of patients with chronic hepatitis C infection (2013). There is also evidence for ongoing transmission of hepatitis $\mathrm{C}$ from parents to children. (Strickland G., 2013)

Liver is largest organ in the body, weighing an average of $1.5 \mathrm{~kg}$. It is situated below the diaphragm in the right upper abdomen. Liver is highly vascular which receives its blood supply from the hepatic

artery and the hepatic portal vein from the intestine and spleen. (Francis, 2014)

Liver disease is the third most common cause of death among individuals between the ages of 25 and 59 year, and the seventh most common cause of all disease-related deaths. (Gray \& Lewis, 2013) Liver biopsies are sometimes called percutaneous liver biopsies, because the tissue sample is obtained by going through the patient's skin. This is a useful diagnostic procedure with very low risk and little discomfort to the patient. ( Bravo \& et al., (2014)

Liver biopsy is usually done to evaluate the extent of damage that has occurred to the liver because of chronic and acute disease processes or toxic injury. Biopsies are often performed to identify abnormalities in liver tissues after other techniques have failed to yield clear results. No specific contraindications exist, but attempts should be made to correct coagulation derangements before proceeding, Lack of venous access is a limitation for this procedure.(Krucik, 2013)

Liver biopsy is performed for two main reasons: diagnosis of liver condition itself, and as an adjunct to an existing surgical procedure. Recently, it has become possible to employ both approaches with minimal invasiveness using the transjugular route or under the guidance of ultrasound, computed tomography, or laparoscopic and endoscopic 
ultrasound. Techniques for liver tissue sampling include percutaneous liver biopsy, transjugular liver biopsy, laparoscopic liver biopsy, and transgastric liver biopsy.(Flemming et al., 2009)

Egypt has a very high prevalence of $\mathrm{HCV}$ and a high morbidity and mortality from chronic liver disease, cirrhosis, and hepatocellular carcinoma. Approximately $20 \%$ of Egyptian blood donors are anti-HCV positive. Egypt has higher rates of $\mathrm{HCV}$ than neighboring countries as well as other countries in the world with comparable socioeconomic conditions and hygienic standards for invasive medical, dental, or paramedical procedures. The strong homogeneity of HCV subtypes found in Egypt (mostly 4a) suggests an epidemic spread of HCV. Since a history of injection treatment has been implicated as a risk factor for $\mathrm{HCV}$, a prime candidate to explain the high prevalence of $\mathrm{HCV}$ in Egypt is the past practice of parenteral therapy for schistosomiasis. The large reservoir of chronic HCV infection established in the course of these campaigns remains likely to be responsible for the high prevalence of $\mathrm{HCV}$ morbidity and may be largely responsible for the continued endemic transmission of HCV in Egypt today.(WHO, 2013)

Complications of liver biopsy are post biopsy pain with or without radiation to the right shoulder occurs in up to one third of patients, intra-peritoneal bleeding is the most serious complication, Patients who have clinical evidence of hemodynamically significant bleeding, the major risk of having a standard liver biopsy is internal bleeding at the site where the needle enters the liver bleeding. (Caldwel, 2010)

The nurses role in the outpatient hepatitis virus clinic and gastroenterology unit include pre and post procedure planning, assistance during the procedure, patient and family education, and emotional support. It is important to develop a trusting rapport with patients undergoing a liver biopsy. In addition, confident assistance with the procedure and correct Positioning of the patient lead to a successful procedure as well as to an uneventful recovery. (National Digestive Diseases. 2014)

\section{Significance of the study}

Through the researcher experience, had observed that the patients undergoing liver biopsy needed special guidelines to improve the patients, outcome. This study was the first study that provides nursing guidelines for patients undergoing liver biopsy in this geographical location which will help such groups of patients. About 200 cases in outpatient hepatitis viruses' clinic and 60 cases in gastroenterology department were done at Assiut University Hospital during 6 month according to hospital record 2013.

\section{Aims of the study are}

This study aim to assess patient knowledge about liver biopsy,andstudy the effect of implementing suggested nursing teaching guidelines for Patients undergoing liver biopsy and to evaluate the effect of implementing suggested nursing teaching guidelines for Patients undergoing liver biopsy on their outcome Research Hypotheses

To fulfill the aim of this study the following research hypotheses were formulated:

(1) The post mean knowledge scores of patients will be higher than pre mean knowledge scores.

(2) The incidence of complications for patients who had undergoing liver biopsy. after post implementing suggested nursing teaching guidelines will be less than that pre of implementing suggested nursing teaching guidelines.

(3) A positive relationship will exist between pre and post implementing suggested nursing teaching guidelines for patients undergoing liver biopsy.

\section{Subjects and Methods}

Research design; Quasi experimental design was utilized in this study.

Technical design: It includes study setting, subject,tool of data collection.

Setting; This study was conducted in outpatient hepatitis viruses' clinic and gastroenterology Unit at Assiut University Hospital.

Subjects; A convenience sample of (200) adult patients (18- 65 years) female and male who was admitted in gastroenterology unit and outpatient hepatitis viruses clinic at Assiut University Hospital.

Tool of the study: It was used one tool for data collection for this study.

Tool: patients knowledge regarding liver biopsy questionnaire interview schedule

Patient's questionnaire sheet. It was developed by the researcher based on current national and international literatures it includes four parts;

Part (1): Sociodemographic variables of study sample (200 patients), including age, sex, marital status, level of education, occupation and medical diagnosis . suggested nursing teaching guidelines for patients undergoing liver biopsy.

Part (2): assess patient's Knowledge regarding liver biopsy on admission after two weeks. This tool was used before and after the implementation of suggested nursing teaching guidelines for patients undergoing liver biopsy. 
b-Assess patients' knowledge during liver biopsy which include: fear and position of liver biopsy pre and post (after two weeks).

c- Assess Patients' knowledge after liver biopsy which includes: feeding, pain, nausea, vomiting, discharge plane, driving, dressing, bath, working, bleeding, reason for return the hospital and result of liver biopsy pre and post (after two weeks).

Part (3): Medical data which includes: medical diagnosis and vital signs (pre, immediate and after 2 hours (temperature, pulse, respiration and blood pressure) .

Part (4): laboratory investigation before taking liver biopsy which includes: (complete blood picture, prothrombin time, liver function, kidney function and Hepatitis marker).

Scoring system: The total number of questions was (35). Each complete answer was get score of (1) but incorrect answer was get score of (0).Patient who scored $(50 \%)$ or less were considered as having "poor" knowledge. Those who scored (51\%-70\%) were considered having "fair" knowledge while those scored $(71 \%-100 \%)$ were considered as having "good" knowledge.

Nursing guidelines for Patients undergoing liver biopsy, \{Booklet\}.

It construction of developed nursing guidelines for Patients undergoing liver biopsy. Nursing guidelines was developed by the researcher based on the patients' needs that can help patients in provision of a safe and effective care for liver biopsy and improvement patient outcome.

Operational design: The Operational design includes preparatory phase,face and content validity, pilot study and ethical considerations.

preparatory phase: It was included reviewing of literature and different studies related to evaluate the effect of implementing suggested nursing teaching guidelines for Patients undergoing liver biopsy on their outcome.

Tool testing and pilot study: The content and validity was done by (5) expertise from. medical surgical nursing field and medical staff. A pilot study was applied on $10 \%$ of studied patients undergoing liver biopsy before starting data collection, the aim of pilot study was to evaluate the inability applicability and clarity of the developed tool, time needed for filling in the sheet, moreover, to identify problems that may encountered during the actual data collection.Necessary modifications were done and patients guideline included in the pilot study were excluded from the study group.

Statistical design: The data obtained had reviewed, prepared for computer entry, coded, analyzed and tabulated. Descriptive statistics (frequencies and percentages, mean and standard deviation, i.e.) were done using computer program (SPSS) version(22). Independent sample T test, Chi-square and One-wayANOVA tests used in relationship between patients' (pre \& post)knowledge. It considered significant when P. value less than (0.05).

Limitation of the study: The barriers during collecting data concerning the thesis about assessment of patients knowledge e related to liver biopsy. The length of stay of liver biopsy patients was maximum one day, there is no enough time to ensure from understand of patients. 


\section{Results}

Table (1): Frequency distribution of study sample related to socio-demographic characteristics of studied patients.

\begin{tabular}{|c|c|c|}
\hline \multirow{2}{*}{ Items } & \multicolumn{2}{|c|}{ Study patient } \\
\hline & $\mathrm{N}=\mathbf{2 0 0}$ & $\%$ \\
\hline \multicolumn{3}{|l|}{ Gender } \\
\hline Male & 171 & 85.5 \\
\hline Female & 29 & 14.5 \\
\hline \multicolumn{3}{|l|}{ Age (year) } \\
\hline$<20$ years & 1 & 0.5 \\
\hline 20 to 35 years & 98 & 49.0 \\
\hline 36 to 50 years & 86 & 43.0 \\
\hline$>50$ years & 15 & 7.5 \\
\hline Mean \pm S.D. & \multicolumn{2}{|c|}{$36.1 \pm 1.05$} \\
\hline \multicolumn{3}{|l|}{ Diagnosis } \\
\hline Hepatitis C Virus+ & 194 & 97.0 \\
\hline Hepatitis B Virus+VE & 6 & 3.0 \\
\hline \multicolumn{3}{|l|}{ Occupation } \\
\hline Employee & 31 & 15.5 \\
\hline Unemployed & 72 & 36.0 \\
\hline Farmer & 66 & 33.0 \\
\hline Student & 6 & 3.0 \\
\hline Craftsman work & 25 & 12.5 \\
\hline \multicolumn{3}{|l|}{ Level of education } \\
\hline Illiterate & 90 & 45.0 \\
\hline Read \&write & 57 & 28.5 \\
\hline Secondary & 49 & 24.5 \\
\hline University & 4 & 2.0 \\
\hline \multicolumn{3}{|l|}{ Marital status } \\
\hline Single & 50 & 25.0 \\
\hline Married & 144 & 72.0 \\
\hline Divorced & 2 & 1.0 \\
\hline Widowed & 4 & 2.0 \\
\hline
\end{tabular}

Table (2) : Relation between Patients' knowledge (pre\&post nursing guidelines) about liver biopsy.

\begin{tabular}{|l|c|c|c|c|}
\hline \multicolumn{1}{|c|}{ Items } & $\begin{array}{c}\text { Pre } \\
\text { guidelines }\end{array}$ & $\begin{array}{c}\text { Post } \\
\text { guidelines }\end{array}$ & \multirow{2}{*}{ T-Test } & \multirow{2}{*}{ P-value } \\
\cline { 2 - 4 } & Mean \pm SD & Mean \pm SD & & \\
\hline 1-Definition of liver. & $0.08 \pm 0.2$ & $1.4 \pm 0.5$ & 314.8 & $0.000^{* * *}$ \\
\hline 2-Function of the liver. & $0.1 \pm 0.3$ & $1.2 \pm 0.4$ & 49.725 & $0.000^{* * *}$ \\
\hline 3-Definition of of liver biopsy . & $0.09 \pm 0.3$ & $1.9 \pm 0.3$ & 0.256 & 0.613 \\
\hline 4-Reasons for taking liver biopsy . & $0.7 \pm 0.4$ & $1.2 \pm 0.4$ & 0.059 & 0.807 \\
\hline 5-Ways to take a sample from liver. & $0.07 \pm 0.2$ & $1.1 \pm 0.1$ & 3.064 & $0.000^{* * *}$ \\
\hline What is this way? & $0.08 \pm 0.2$ & $1.1 \pm 0.1$ & 18.359 & $0.000^{* * *}$ \\
\hline 6-A biopsy of the liver requires anesthesia. & $0.1 \pm 0.3$ & $1.7 \pm 0.4$ & 42.023 & $0.000^{* * *}$ \\
\hline -Type of anesthesia & $0.07 \pm 0.2$ & $1.1 \pm 0.1$ & 28.922 & $0.000^{* * *}$ \\
\hline 7-Contraindications of liver biopsy. & $0.09 \pm 0.2$ & $1.1 \pm 0.2$ & 6.957 & $0.009 * *$ \\
\hline 8- Complications of liver biopsy. & $0.9 \pm 0.1$ & $1.1 \pm 0.1$ & 4.071 & $0.044 *$ \\
\hline 9- Do take breakfast? & $0.1 \pm 0.3$ & $1.6 \pm 0.4$ & 142.2 & $0.000^{* * *}$ \\
\hline
\end{tabular}




\begin{tabular}{|c|c|c|c|c|}
\hline \multirow[t]{2}{*}{ Items } & $\begin{array}{c}\text { Pre } \\
\text { guidelines } \\
\end{array}$ & $\begin{array}{c}\text { Post } \\
\text { guidelines } \\
\end{array}$ & \multirow[t]{2}{*}{ T-Test } & \multirow[t]{2}{*}{ P-value } \\
\hline & Mean \pm SD & Mean \pm SD & & \\
\hline 10-Feel worry when begin to take of liver biopsy . & $0.1 \pm 0.3$ & $1.8 \pm 0.3$ & 4.686 & $0.031 *$ \\
\hline $\begin{array}{l}\text { 11-Instructions that follow after taking a sample from } \\
\text { the liver }\end{array}$ & $0.07 \pm 0.2$ & $1.1 \pm 0.1$ & 47.218 & $0.000 * * *$ \\
\hline 12-Correct position during liver biopsy. & $0.8 \pm 0.2$ & $1.1 \pm 0.3$ & 6.479 & $0.011^{*}$ \\
\hline - If yes, what is it? & $0.07 \pm 0.2$ & $1.5 \pm 0.3$ & 438.2 & $0.000 * * *$ \\
\hline 13-Time to eat and drink after liver biopsy. & $0.07 \pm 0.2$ & $1.1 \pm 0.2$ & 0.000 & 1.000 \\
\hline 14-Action when feel nauseous or vomit after eating. & $0.08 \pm 0.2$ & $1.1 \pm 0.3$ & 34.043 & $0.000 * * *$ \\
\hline 15-Action when feel pain after taking liver biopsy. & $0.08 \pm 0.3$ & $1.8 \pm 0.3$ & 31.181 & $0.000 * * *$ \\
\hline 16-Time to leave the hospital after taking liver biopsy. & $0.7 \pm 0.2$ & $1.1 \pm 0.3$ & 220160 & $0.000 * * *$ \\
\hline 17-Time to drive a car after taking liver biopsy. & $0.08 \pm 0.3$ & $1.2 \pm 0.4$ & 43.639 & $0.000 * * *$ \\
\hline $\begin{array}{l}\text { 18-Action if have a bleeding from the site of liver } \\
\text { biopsy. }\end{array}$ & $0.1 \pm 0.4$ & $1.7 \pm 0.4$ & 19.183 & $0.000 * * *$ \\
\hline $\begin{array}{l}\text { 19-Time to go out of the house after taking liver } \\
\text { biopsy. }\end{array}$ & $0.07 \pm 0.2$ & $1.1 \pm 0.2$ & 2.059 & 0.152 \\
\hline 20-Time to leave bed and move freely. & $0.07 \pm 0.2$ & $1.1 \pm 0.3$ & 18.415 & $0.000 * * *$ \\
\hline 21-Time to take a bath. & $0.09 \pm 0.3$ & $1.2 \pm 0.4$ & 69.856 & $0.000 * * *$ \\
\hline 22-Time to dress off operation clothes. & $0.1 \pm 0.4$ & $1.5 \pm 0.5$ & 128.570 & $0.000 * * *$ \\
\hline 23-Action if feel dizzy. & $0.1 \pm 0.4$ & $1.8 \pm 0.3$ & 0.307 & 0.580 \\
\hline 24-Time to go work after taking the biopsy. & $0.08 \pm 0.2$ & $1.1 \pm 0.2$ & 0.146 & 0.702 \\
\hline 25-When you can raise heavy things? & $0.08 \pm 0.2$ & $1.1 \pm 0.2$ & 8.530 & $0.004 * *$ \\
\hline $\begin{array}{l}\text { 26-Reasons that make go to hospital immediately } \\
\text { without thinking. }\end{array}$ & $0.1 \pm 0.3$ & $1.6 \pm 0.4$ & 106.828 & $0.000 * * *$ \\
\hline 27-Time of outcome the results of the sample & $0.07 \pm 0.2$ & $1.1 \pm 0.2$ & 4.299 & $0.039 *$ \\
\hline
\end{tabular}

Table (3) : Percentage distribution of patients' knowledge (pre-post) guideline about liver biopsy.

\begin{tabular}{|c|c|c|c|c|}
\hline \multirow{2}{*}{ Patients' knowledge mor than } & \multicolumn{2}{|c|}{ Pre- guidelines } & \multicolumn{2}{c|}{ Post- guidelines } \\
\cline { 2 - 5 } & $\mathbf{N}=\mathbf{( 2 0 0 )}$ & $\mathbf{\%}$ & $\mathbf{N}=\mathbf{( 2 0 0 )}$ & $\%$ \\
\hline Poor (<=50\%) & 187 & 93.5 & 0 & 0.0 \\
\hline Fair (50\% to 70\%) & 13 & 6.5 & 184 & 92.0 \\
\hline Good (70\% to 100\%) & 0 & 0.0 & 16 & 8.0 \\
\hline Total & 200 & 100.0 & 200 & 100.0 \\
\hline
\end{tabular}

Table (1) : shows that; majority of patients are male with percentage $(85.5 \%)$.Nearly half of patients their age are ranged from 20 to 35 years with percentage (49\%). Third of patient are unemployed and other third are farmer with percentage $36.0 \%$ and $33.0 \%$ respectively). $45 \%$ of patients were illiterate. $72 \%$ of patients were married.

Table (2) : demonstrated that; there are statistical difference between patients' knowledge (pre \& post) about liver biopsy.

Table (3) : cleared that; in one hand vast majority of patients had poor level in preknowledge with percentage (93.5\%). But in other hand vast majority of patients had fair level in post-knowledge with percentage $(92.0 \%)$.

\section{Discussion}

As regards socio-demographic data of patients, nearly half of patients their ages ranged from 20 -35 years this result is in line with the study of American Liver Foundation, (2013). which reported that liver biopsy is common, occurring among patients at an early age Based on the results of the present study, the majority of patients are male and married, This result was supported by Center for Continuing Education(2014). 
The incidence of liver biopsy among men is higher than in women.

The present study revealed that vast majority of indications for liver biopsy were hepatitis C. This study finding was supported by François \& Cadranel,( 2010); who reported that the most common indications for liver biopsy were hepatitis C., then hepatitis B and abnormal liver function tests. Discussion classify into three phases

Pre preparation phase knowledge

The present study revealed that in one hand vast majority of patients had poor level in pre-knowledge. But in other hand vast majority of patients had fair level in post-knowledge. This result in the same line with the study of Bonnie,(2012). which reported that the level of knowledge among patients was fair regarding patient education and treatment.

During biopsy knowledge

Mayberry \& Wicks (2010), documented that the in service nursing teaching has a beneficial effect in improving the patients knowledge and instruction and also recommended that educational programs should be organized according to the patients needs with continuous guidelines.

\section{After biopsy knowledge}

The present study showed that improvement in the patient level of knowledge regarding the guidelines offered for patients undergoing liver biopsy. The previous result was supported by Soldevila,(2013), which reported that the level of knowledge had improvement after implementing guidelines for patients about liver biopsy .

\section{Conclusion}

Based on finding of this study, it can be concluded that

Vast majority of patients undergoing liver biopsy had deficient in knowledge liver biopsy.

So, They need guidelines to improve their level of knowledge to avoid complication after liver biopsy.

\section{Recommendations}

Based on the findings of the present study the following recommendations are suggested:

- Liver biopsy should be taught to trainees by experts, highly experienced in the practice of liver biopsy and management of its

potential complications.

- An orientation program should be prepared for patients undergoing liver biopsy according to their needs.

- The nursing teaching guidelines should be given by the professional nurses and should be aware of liver disease complication, how to prevent it and how to deal with it when develop.
- The nurse should check the patient's records prior to the liver biopsy.

to see whether he / she is taking any other medications that may affect

blood clotting.

- Replication of this study by using a large number of patients undergoing liver biopsy from different geographical areas in Egypt.

- Prior to performance of liver biopsy, patients should be educated about their liver disease and about investigations other than liver biopsy (if any) that may also provide diagnostic information

- Making and provide teaching aids (e.g. posters) to enhance liver biopsy procedure for health care personnel or clients and putting it at visible place.

\section{References}

1. American Liver Foundation, (2013): J., Clin Liver Biopsy Defin. Diseases; 5: 263-276.

2. Assiut University Hospital statistics record, (2013) : Assiut University Hospital Egypt

3. Bonnie, K., (2012): Patient Education and Treatment Strategies Implemented at a Pharmacist-Managed Hepatitis C Virus Vol, (25), Issue (9), pages 1230-1241 .Journal of Human Pharmacology and Drug Therapy.

4. Bravo A., Sheth S., Chopra S., (2014): Liver biopsy. N., Engl, J, Vol. (17), Issue (12) ,Pp $: 344: 495$.

5. Caldwel S., ( 2010):Bleeding Complication with Liver Biopsy: Is It Predictable?," Clin Gastroenterol Hepatol, Vol,( 8) Issue(39), Pp:826 829.

6. Center for Continuing Education(2014).9500 Euclid Avenue, KK31, Cleveland Clinic Foundation, OH 4419.

7. Flemming J., Hurlbut D., Mussari B., Hookey L., (2009); Liver biopsies for chronic hepatitis C: Should nonultrasound-guided biopsies be abandoned? Can J Gastroenterol, Vol(1), Issue. (23)Pp:425-30.

8. Francis ,K.(2014): Anatomy and Physiology of the Liver Phil. Trans. R. Soc. Lond.,711-770.

9. François, J., and Cadranel, (2010): Unité d'hépatologie, Centre Hospitalier Laennec, Creil, France Cellule PMSI, AP-HP, Hôpital Beaujon, Clichy, France Service d'hépatologie, availability (francoise.degos@bjn.ap-hop-paris.fr).

10. Gray H., Lewis W., (2013): Anatomy of the Human Body. 20th Ed. New York, NY: Bartleby. results from the Hepatitis C Antiviral Long-term Treatment Against Cirrhosis Trial. Hepatology 55(4):1019-29. 
11. George K., (2013): Healthline Medical Review and Advisory Board.

12. Mayberry, A., Wicks, Y., Rees, R., Playford, (2010): Liver Biopsy under Ultrasound Control: Implications for Training in the Calman Era," Gut, 45628629.

13. National Digestive Diseases. (2014): Information Clearinghouse NIH publication Issue..(09) Pp4731.

14. Soldevila-Pico C., (2013): Patient information: Liver biopsy (Beyond the Basics).

15. Strickland G., (2013): Liver disease in Egypt: hepatitis $\mathrm{C}$ superseded schistosomiasis as a result of iatrogenic and biological factors. Hepatology, 43(5):915-922. PubMed Abstract Publisher Full Text

16. World Health Organization, (WHO) (2013): Hepatitis C - global prevalence (update). Weekly Epidemiological Record,Vol, (74), Issue(18). Pp:425-427. 